\title{
¿Podemos mejorar la calidad de la escritura en el posgrado? Algunas respuestas a partir de un proceso de investigación-acción ${ }^{1}$
}

Podemos melhorar a qualidade da escrita nos programas de Pós-Graduação? Algumas respostas a partir de um processo de pesquisa-ação

Iris Viviana Bosio*

*Universidad Nacional de Cuyo, Mendoza / Argentina irisvivianabosio@ffyl.uncu.edu.ar

\begin{abstract}
RESUMEN: Este artículo describe el desarrollo de un proceso de investigación-acción en un taller de escritura de ensayos académicos en una carrera de doctorado en Arquitectura. Se trata de un estudio de caso, cuyos datos provienen de escritos originales de los doctorandos y de actas de evaluación correspondientes a las distintas instancias de producción y corrección propuestas en el taller. Los resultados sugieren que la modelización y la explicitación del proceso de escritura, el entrenamiento estratégico sistemático en géneros académicos y un conjunto de criterios de evaluación coherentes con dicha explicitación contribuyen al incremento de la calidad de la producción escrita en el nivel de posgrado.
\end{abstract}

PALABRAS CLAVE: Lingüística aplicada; alfabetización académica; producción escrita; posgrado.

RESUMO: Este artigo descreve o desenvolvimento de um processo de pesquisa-ação em uma oficina de redação de ensaios acadêmicos em um programa de doutorado em Arquitetura. É um estudo de caso, cujos dados provêm dos escritos originais dos doutorandos e de relatórios de avaliação correspondentes às diferentes instâncias de produção e correção propostas na

\footnotetext{
${ }^{1}$ La propuesta de esta investigación, en una versión preliminar y parcial, fue presentada como ponencia en el XI Congreso Internacional de la Asociación Latinoamericana de Estudios del Discurso (ALED), desarrollado en Buenos Aires, Argentina, del 3 al 6 de noviembre de 2015.
} 
oficina. Os resultados sugerem que a modelagem e explicitação do processo de escrita, o treinamento estratégico e sistemático em gêneros acadêmicos e um conjunto de critérios de avaliação coerentes com essa explicitação contribuem para o aumento da qualidade da produção escrita nos programas de PósGraduação.

PALAVRAS-CHAVE: Linguística aplicada; letramento acadêmico; produção escrita; programas de pós-graduação.

\section{Breve presentación introductoria}

La escritura en el posgrado supone un complejo proceso que involucra no solo factores de orden lingüístico. En este nivel, las producciones textuales exigen, además, el dominio de un campo especializado, tienen una función específica delimitada en la comunidad académica, poseen una estructura fuertemente convencionalizada y características muy restrictivas respecto del uso del sistema de la lengua escrita general. Los propósitos de este trabajo se orientan a la descripción de un proceso de intervención en la producción de ensayos y a una interpretación de los resultados respecto de la calidad de las producciones, en el marco de un taller de escritura académico-científica en una carrera de doctorado en Arquitectura. La modelización y los criterios de evaluación se basan en la propuesta de Cubo, Puiatti y Lacon (2012), reformulada en cuanto a cantidad y a propiedades de los modelos mentales involucrados en el proceso de producción. Se trata de una investigación aplicada, de alcance descriptivo y explicativo, con un enfoque cualitativo de investigación-acción, basado en un estudio de caso. Los datos provienen de ensayos originales escritos por doctorandos, y actas de evaluación correspondientes a las distintas instancias de producción y corrección propuestas en el taller. En este primer acercamiento desde esta modalidad de investigación, los resultados preliminares indican que la explicitación de los procesos de producción de discursos académicocientíficos, el entrenamiento estratégico sistemático y un conjunto de criterios de evaluación consistentes colaboran en el aumento de la calidad de la producción de ensayos académicos en el nivel de doctorado.

\section{Propósitos}

Un proceso disciplinado de investigación-acción supone una espiral de actividades en esta secuencia (ELLIOT, 2000): 
- Aclaración y diagnóstico de una situación problemática en la práctica

- Formulación de estrategias de acción para resolver el problema

- Implantación y evaluación de las estrategias de acción

- Aclaración y diagnóstico posteriores de la situación problemática (y así sucesivamente en la siguiente espiral de reflexión y acción)

A partir de la situación en torno al problema de la escritura académica en el nivel del posgrado, este trabajo, basado en un estudio de caso desde la tradición de investigación cualitativa, estuvo orientado por los siguientes propósitos:

a) Diseñar y poner en práctica un proceso de intervención educativa sustentado en un modelo sociocognitivo de producción discursiva (con base en representaciones pragmáticas, semánticas, textuales y normativas), tanto en la tarea de escritura de ensayos académicos por parte de los alumnos como en la de confección y llenado de grillas de evaluación por parte de los docentes;

b) Describir el proceso de intervención en la producción de ensayos académicos en el marco de un taller de escritura académico-científica en una carrera de doctorado en Arquitectura;

c) Interpretar holísticamente la eficacia del proceso de intervención, integrando sus distintas fases y tomando como criterio orientador la calidad de las producciones escritas a lo largo de las distintas instancias de escritura y evaluación previstas en el taller.

En este punto, es necesario aclarar que entiendo por "intervención" el conjunto de acciones planteadas con miras a conseguir, en un contexto institucional específico, unos objetivos educativos socialmente determinados (ALZATE PIEDRAHITA et al., 2005).

Desde esta perspectiva, la intervención educativa en medio escolar incluye tres fases que vamos a tener en cuenta para presentar los resultados de este estudio:

- Fase preactiva: referida a las acciones de planificación;

- Fase interactiva: referida a las acciones de actualización en clase;

- Fase post-activa: referida a la evaluación de la actualización. 
La intervención integra, entonces, por una parte, dimensiones didáctico-pedagógicas relacionadas con el proceso de enseñanza y aprendizaje; por otra parte, dimensiones organizacionales relacionadas con la gestión de la clase en tanto espacio institucional y socialmente determinado.

\section{Contexto conceptual}

La "alfabetización académica" o "literacidad académica" fue conceptualizada en una de las publicaciones en español pioneras en la materia como "el conjunto de nociones y estrategias necesarias para participar en la cultura discursiva de las disciplinas así como en las actividades de producción y análisis de textos requeridos para aprender en la universidad" (CARLINO, 2003, p. 410). Paralelamente al desarrollo que ha tenido la investigación en alfabetización académica en el último tiempo, el concepto se ha ido revisando, actualizando y redefiniendo, para incorporar los escenarios de prácticas de lectura y escritura situados y continuos en el transcurso de la formación académica, disciplinar y profesional e incluir a los demás actores del proceso que supone la literacidad, no solamente a los estudiantes (CARLINO, 2013; IBÁÑEZ; GONZÁLEZ, 2017; PARODI, 2008).

Como ya adelantamos, este trabajo se centrará específicamente en la problemática de la escritura académica en el nivel de doctorado, pero se enmarca de manera general en la línea de proyectos de investigación en alfabetización académica acreditados y ejecutados ininterrumpidamente desde 1998 en la Universidad Nacional de Cuyo (Mendoza, Argentina).

El problema que ya por aquellos años observábamos es que los estudiantes universitarios de grado y posgrado, los becarios y los investigadores noveles necesitaban resolver tareas de escritura especializada en el ámbito académico-científico, insertas en una variedad de situaciones con especificidades y convenciones propias. Nos estamos refiriendo, entonces, a un tipo de interacción comunicativa que plantea, ciertamente, necesidades de escritura que van más allá de los objetivos básicos de comunicarse y aprender nueva información y que se proyecta, por lo tanto, hacia otras dimensiones. Sin embargo, la preocupación por esta problemática en los últimos años del siglo XX y los primeros del siglo XXI se dirigió predominantemente hacia la escritura académica en inglés (entre otros, 
BAZERMAN, 2005, 2009; BHATIA, 1993; GRABE; KAPLAN, 1996; HALLIDAY; MARTIN, 1993; HYLAND, 1999; MARTIN; ROSE, 2003; PALTRIDGE, 1997, 2001; SCHRÖDER, 1991; SWALES, 1990, 2004). Cubo de Severino y Castro de Castillo (2005, p. 15) afirmaban hace más de una década atrás: "Nuestros estudiantes, que deben escribir en español, no disponen de suficiente material bibliográfico que los ayude a conocer cómo escriben los miembros de su comunidad de discurso en su propia lengua". Al respecto, Carlino (2013) da cuenta de un cambio radical en los últimos diez años, mediante el repaso de algunas publicaciones e iniciativas pedagógicas en el ámbito universitario argentino. Pero este cambio es sensible no solo en nuestro país: hoy, la alfabetización académica en español se ha instalado como objeto de estudio. En el ámbito latinoamericano -por citar un ejemplo-, contamos con redes y asociaciones científicas e interuniversitarias que promueven la discusión y la difusión de resultados de investigación en alfabetización académica en las distintas convocatorias de sus publicaciones, congresos y simposios (desde la ya tradicional "Cátedra UNESCO para la lectura y la escritura en América Latina”, con sedes y subsedes en universidades de toda la región; hasta la novel ALES -Asociación Latinoamericana de Estudios de la Escritura en Educación Superior y Contextos Profesionales-). El estudio de la alfabetización académica en español se ha ido profundizando, complejizando y especializando en función de intereses específicos de indagación, en el marco de programas y proyectos de investigación acreditados por universidades y agencias (entre otros, BOSIO, 2016-2018; PARODI, 2011; VENEGAS, 2016). Valgan como ejemplos las siguientes menciones de investigaciones en las disciplinas (PARODI, 2010; MANGHI, 2013), en los géneros producidos (CUBO, 2005; CUBO; BOSIO, 2012; PADILLA; DOUGLAS; LÓPEZ, 2010), en las propuestas didáctico-pedagógicas (IBÁÑEZ; GONZÁLEZ, 2017; NAVARRO, 2014; OLAIZOLA, 2011; VENEGAS et al., 2015) y en los distintos niveles del sistema educativo (NOTHSTEIN; VALENTE, 2016; PÉREZ GAZTELU; ZULAIKA IJURKO, 2014; SOSA; MAZZUCHINO, 2017; SOTOMAYOR et al., 2016).

Para el estudio de los procesos de producción y la evaluación de estrategias de escritura en el ámbito académico-científico, nuestro equipo de investigación partió inicialmente, a fines de los años 90, del modelo teórico de Van Dijk y Kintsch (1983), que enfatiza el carácter estratégico y flexible 
del proceso de producción y establece relaciones con el de comprensión. Estos autores desarrollaron el modelo a partir de tres componentes básicos, interconectados en la planificación de un escrito y que exigen la activación de representaciones mentales en el escritor: plan global, plan pragmático y plan semántico. A lo largo de nuestra línea de investigación, y con el fin de desarrollar con más detalle algunos aspectos o de solucionar problemas que surgieron frente a los datos empíricos, el marco teórico se fue ampliando y complementando con otras propuestas compatibles (entre otros, BAZERMAN; BONINI; FIGUEIREDO, 2009; HALLIDAY; MARTIN, 1993; HAYES, 1996; HYLAND, 2003; MILLIAM; CAMPS, 2000). Como resultado de este permanente estudio, cotejo y actualización, propusimos una serie de estrategias lingǘsticas, cognitivas y metacognitivas que responden a tres tipos de representaciones mentales (CUBO; BOSIO, 2012): Modelo de situación comunicativa (pragmático), Modelo de evento (semántico) y Modelo textual (discursivo). En la Tabla 1 presento una reformulación de la propuesta original, que incluye la categoría "Modelo de corrección normativa", en relación con la representación de categorías gramaticales y ortográficas del español emergentes como problemáticas en el proceso de la escritura académica. También he asociado a cada uno de los modelos algunas preguntas estratégicas que tienen lugar en el proceso de escritura y que orientan, a su vez, la definición de las preguntas de esta investigación, como veremos más adelante: 
TABLA 1 - Modelo de producción de discurso académico basado en el procesamiento cognitivo y metacognitivo

\begin{tabular}{|c|c|c|}
\hline MODELO & $\begin{array}{l}\text { REPRESENTACIÓN } \\
\text { MENTAL DE }\end{array}$ & PREGUNTAS ESTRATÉGICAS \\
\hline $\begin{array}{l}\text { Situación } \\
\text { comunicativa } \\
\text { (espacio/tiempo, } \\
\text { intenciones, ideología, } \\
\text { emociones del } \\
\text { autor y del posible } \\
\text { lector, sistemas } \\
\text { de cooperación y } \\
\text { cortesía) }\end{array}$ & $\begin{array}{l}\text { Función/propósito } \\
\text { comunicativo del género } \\
\text { Relaciones socio- } \\
\text { contextuales entre lector- } \\
\text { evaluador y autor-evaluado }\end{array}$ & $\begin{array}{l}\text { ¿Por qué y para qué voy a escribir? } \\
\text { ¿Quiénes podrían evaluar mi escrito? } \\
\text { ¿Cómo voy a hacer para convencerlos de } \\
\text { mi propuesta? ¿Me conviene presentar } \\
\text { esta idea como una afirmación o } \\
\text { como una pregunta? ¿Cómo presento } \\
\text { la importancia de la investigación sin } \\
\text { incomodar al evaluador? }\end{array}$ \\
\hline $\begin{array}{l}\text { Evento de } \\
\text { investigación } \\
\text { (individuos y hechos } \\
\text { objeto de estudio; } \\
\text { propiedades y } \\
\text { relaciones entre } \\
\text { los individuos y los } \\
\text { hechos) }\end{array}$ & Contenido del discurso & $\begin{array}{l}\text { ¿Qué quiero comunicar? ¿Qué } \\
\text { conocimiento quiero crear y mostrar } \\
\text { en mi trabajo? ¿Cuál es el aporte de } \\
\text { mi investigación? ¿Cuál es el objeto } \\
\text { de mi investigación? ¿Cuáles son sus } \\
\text { características? ¿Cómo se relaciona mi } \\
\text { investigación con otras investigaciones } \\
\text { sobre el mismo objeto? }\end{array}$ \\
\hline $\begin{array}{l}\text { Texto } \\
\text { (estructura del } \\
\text { discurso, género } \\
\text { académico y sus } \\
\text { convenciones) }\end{array}$ & $\begin{array}{l}\text { Escritura organizacional } \\
\text { Convenciones genéricas y } \\
\text { disciplinares }\end{array}$ & $\begin{array}{l}\text { ¿Cómo me imagino que debe ser un } \\
\text { proyecto/artículo/ensayo, etc.? ¿Qué } \\
\text { partes va a tener el texto? ¿Qué voy a } \\
\text { escribir en cada parte? ¿Cómo voy a } \\
\text { distribuir la información? ¿Cómo voy } \\
\text { a citar la bibliografía? ¿Cómo se hacen } \\
\text { las referencias? ¿Voy a incluir gráficos? } \\
\text { ¿Cómo voy a relacionarlos con el texto } \\
\text { verbal escrito? }\end{array}$ \\
\hline $\begin{array}{l}\text { Corrección } \\
\text { normativa }\end{array}$ & $\begin{array}{l}\text { Corrección ortográfica } \\
\text { Corrección gramatical }\end{array}$ & $\begin{array}{l}\text { ¿Mi texto estará bien escrito? ¿Pongo } \\
\text { coma o punto? ¿Cuándo coloco punto y } \\
\text { coma y cuándo punto seguido? ¿Escribo } \\
\text { esta palabra con mayúscula? ¿Este } \\
\text { gerundio está bien usado? ¿Pongo punto } \\
\text { después de un título? ¿Esta palabra } \\
\text { compuesta va con guion? ¿Uso "el cual", } \\
\text { "lo cual", "la cual", "quien" o "que”? } \\
\text { ¿Esta oración es muy larga? }\end{array}$ \\
\hline
\end{tabular}

Fuente: Elaboración propia 


\section{Preguntas preliminares de investigación}

a) ¿Cuáles son las dificultades que enfrentan los doctorandos ante la escritura de un texto académico, particularmente de un ensayo?

b) ¿Qué pautas de escritura serían relevantes y operativas para la enculturación de los estudiantes de posgrado, particularmente en el campo disciplinar y profesional de la Arquitectura?

c) ¿Cómo se puede plantear la enseñanza, sistematizar el aprendizaje y diseñar consecuentemente la evaluación de la escritura de un ensayo académico en el posgrado?

\section{Metodología}

\subsection{Unidad de análisis}

Metodológicamente, el caso es un sistema de actores, relaciones e instituciones sociales, delimitado en tiempo y espacio, que se construye a partir de un determinado y siempre parcial y subjetivo recorte empírico y conceptual de la realidad social. Puede estar constituido por un hecho, un grupo, una relación, una institución, una organización, un proceso social, o una situación o escenario específico (NEIMAN; QUARANTA, 2007). En esta investigación, el caso de estudio es el proceso de intervención en la producción de ensayos académicos, llevado a cabo dentro del marco de un taller de escritura de textos académico-científicos en una carrera de doctorado en Arquitectura.

Se trata de una investigación basada en un estudio de caso instrumental, ya que el caso construido a partir de esta intervención particular podría iluminar un problema empírico más amplio, relacionado con la situación problemática de la enseñanza, el aprendizaje y la evaluación de la escritura académica en el posgrado en general. Asimismo, se espera que los datos empíricos puedan contribuir a la discusión teórica y conceptual que, actualmente, ocupa a los investigadores en alfabetización académica en el nivel superior. 


\subsection{El escenario de observación y los actores del proceso}

El proceso de intervención tuvo lugar en la sede de la Facultad de Arquitectura, Urbanismo y Diseño de la Universidad de Mendoza (Mendoza, Argentina). Tuvo una duración de un año y medio, desde febrero (cuando comenzó la fase preactiva o de planificación) hasta setiembre del año siguiente (cuando se terminó con la fase interactiva o de actualización). Cabe aclarar que, simultáneamente, los doctorandos cursaron otras asignaturas de la carrera, motivo al cual obedece la extensión en el tiempo de la actividad del taller. ${ }^{2}$

El grupo de estudiantes pertenece a una de las últimas ediciones del Doctorado en Arquitectura, carrera de posgrado de modalidad escolarizada. Se trata de un grupo de trece profesionales arquitectos, candidatos al título de Doctor en Arquitectura. De los trece profesionales, cuatro son extranjeros (hablantes nativos de español), y cinco de los de nacionalidad argentina se desempeñan como profesores en el nivel de grado de la Facultad de Arquitectura, Urbanismo y Diseño.

También forman parte de los actores de este caso de estudio por un lado, la directora de la carrera de Doctorado en Arquitectura y la Decana de la Facultad de Arquitectura, Urbanismo y Diseño, quienes participaron activamente en la fase de planificación de la intervención; por otro lado, dos docentes de la carrera de Doctorado en Arquitectura, que cumplieron el rol de evaluadoras de las distintas versiones de los ensayos en lo que concierne al contenido disciplinar de los mismos, como así también el rol de guías en el proceso de reescritura llevado a cabo en el taller "Ensayo académico II". Considero sumamente importante no dejar de lado este dato, ya que la colaboración de las arquitectas en las distintas instancias del taller y su participación en un tribunal interdisciplinario para la evaluación de los ensayos manifiesta el compromiso institucional con la calidad de la escritura académica de los doctorandos. Al respecto, voy a citar las palabras de Federico Navarro en una entrevista publicada en el Boletín de Novedades Educativas:

\footnotetext{
${ }^{2}$ Si bien las autoridades de la carrera prestaron su consentimiento para identificar el programa de doctorado en el que se llevó a cabo la experiencia, para garantizar la anonimización de los sujetos no consignamos datos que permitan identificarlos, como el año en el que tuvo lugar el proceso de intervención o la cohorte a la que pertenecen.
} 
El problema [...] es que la curricularización del dispositivo de escritura en todos los niveles es muy complicada. Lo más sencillo es poner una materia al comienzo de las carreras y punto, o en todo caso poner alguna materia en el posgrado, como escritura de tesis o algo similar. Lo más difícil es pensar dispositivos que interactúen con los docentes de las carreras. La apuesta más interesante, de las que hay algunas experiencias en Argentina, es la formación colaborativa y cruzada entre los docentes de escritura y los docentes de las asignaturas. Las experiencias colaborativas, en mi opinión y en la de varios otros también, son las más enriquecedoras (LATORRE; ALU, 2015).

Finalmente, y de acuerdo con lo expuesto hasta aquí, mi rol como investigadora fue el de observadora participante con un grado de implicación máximo, precisamente por llevar adelante el proceso de intervención en la escritura académica de los doctorandos. Asimismo, previamente al taller de escritura de ensayos académicos que es objeto de análisis en este trabajo, ya había sido implementado un taller de escritura de artículos de investigación y con posterioridad, se implementaría un taller de escritura de proyecto de tesis doctoral. De esta manera, en el abordaje del escenario de trabajo me desempeñé como investigadora, docente y evaluadora del proceso; una estrategia de rol que, de acuerdo con los principios de la investigaciónacción, contribuye a disminuir la brecha entre la investigación disciplinar, la investigación educativa y la práctica docente intuitiva.

\subsection{Tipo de muestra}

Se utilizó un muestreo no probabilístico basado en criterios, que permite que el investigador seleccione directa e intencionadamente los individuos de la población, explicitando las razones de tal selección. La muestra se determinó estableciendo unos pocos criterios, pero de manera totalmente intencionada, de modo que la observación pudiera aportar información variada y cualificada para ensayar respuestas a las preguntas preliminares de investigación:

a) Selección de estudiantes que hubieran necesitado más de una instancia de presentación y evaluación de sus ensayos académicos, para poder evaluar la evolución del proceso de intervención; 
b) Selección de estudiantes en cuyos ensayos se hubieran revelado distintos tipos de dificultades en la tarea de escritura, para poder evaluar la problematicidad de algunos de los rasgos de la producción académica en general y/o de los ensayos en particular.

\subsection{Fuentes de obtención de datos}

Los datos de esta investigación provienen de las distintas versiones de ensayos escritos y entregados por trece doctorandos, de los comentarios escritos y las correcciones de las docentes a las distintas versiones y de las planillas de evaluación que fueron diseñadas, consensuadas y completadas por el tribunal interdisciplinario.

Muy recientemente, los comentarios escritos (CE) en las instancias de evaluación de textos académicos han sido propuestos como un género discursivo (TAPIA-LADINO, 2014; TAPIA-LADINO; ARANCIBIA GUTIÉRREZ; CORREA PÉREZ, 2016; TAPIA-LADINO et al., 2014). Para los propósitos de la presente investigación, resulta pertinente la incorporación de este género emergente como fuente de datos, ya que

Los CE se comportan como un género secundario que contribuye a la construcción de otro [...] los CE son reconocibles como anotaciones -manuales o electrónicas con a lo menos una palabra- que proveen información al escritor en vistas a orientar su proceso de escritura para que esta se ajuste a estándares de calidad propios de la comunidad discursiva en la que se produce. Tal recurso permite a los estudiantes dar saltos críticos en el desarrollo de sus habilidades de escritura (TAPIALADINO; ARANCIBIA GUTIÉRREZ; CORREA PÉREZ, 2016).

\section{Análisis y discusión de los datos}

Los resultados del proceso de investigación-acción llevado a cabo serán presentados en este artículo de acuerdo con las tres fases de la intervención educativa a las que aludimos al inicio de este trabajo: preactiva, interactiva y post-activa. 


\subsection{Fase preactiva o de planificación (febrero a abril)}

Se diseñó, junto con la directora de la carrera de Doctorado en Arquitectura y la Decana de la Facultad de Arquitectura, Urbanismo y Diseño de la Universidad de Mendoza un módulo denominado "El lenguaje científico", en el marco de la asignatura "Proceso y práctica de la investigación". El propósito final de este módulo es la escritura del proyecto de tesis. Para contribuir al logro de este propósito, se planteó la necesidad de un entrenamiento en escritura académico-científica mediante la implementación de dos talleres de escritura, que fueron dedicados a la producción de dos géneros especializados: el artículo de investigación y el ensayo académico. Este último taller fue solicitado por las autoridades, ya que el ensayo es un género mediante el cual los arquitectos habitualmente comunican sus reflexiones y realizan sus contribuciones profesionales a la comunidad de expertos, en revistas especializadas. De esta manera, se pretendió que, mediante el taller, los doctorandos se involucraran en un proceso de enculturación, aunando la satisfacción de una necesidad relacionada con la vida académica del posgrado (entrenamiento en un género académico con vistas a la escritura de una tesis doctoral) con la de una necesidad relacionada con la vida profesional (entrenamiento en un género con vistas a la posibilidad de publicación en revistas de la especialidad):

El concepto de alfabetización académica [...] propone la enculturación académica en los códigos, discursos y convenciones disciplinares, como una forma específica de alfabetización que las instituciones de Educación Superior deberían promover para garantizar que sus estudiantes puedan ser miembros activos de $-\mathrm{y}$ por consiguiente, comunicarse de manera adecuada con- sus respectivas comunidades profesionales (CASTELLÓ, 2014, p. 350).

En este sentido, diseñamos una "Pauta para la edición de artículos y ensayos", emulando las "Indicaciones para los autores" que contiene toda revista especializada y tomando como modelos distintas revistas del campo disciplinar de la arquitectura ${ }^{3}$. La selección de revistas de la especialidad estuvo a cargo de docentes arquitectos de la carrera de Doctorado en Arquitectura. Se previeron tres instancias de presentación y evaluación de los ensayos en el cronograma académico.

${ }^{3} \mathrm{El}$ contenido del documento se encuentra disponible como anexo al final de este artículo. 


\subsection{Fase interactiva o de actualización}

En el marco del módulo "El lenguaje científico", se llevaron a cabo dos talleres: el taller de comprensión escrita "Ensayo académico I" y el taller de producción escrita "Ensayo académico II", de acuerdo con la siguiente secuenciación didáctica.

\subsubsection{Ensayo académico I (mayo): Taller de comprensión}

Previamente a la tarea de escritura propiamente dicha, se organizó un taller de comprensión de ensayos académicos en la disciplina, con el objeto de ofrecerles a los doctorandos los insumos para la elaboración de una representación mental global del evento comunicativo "ensayo académico", que sirviera como punto de partida para el proceso de escritura. El taller incluyó las siguientes actividades:

a) Actividad 1: Los alumnos expusieron (de manera espontánea e intuitiva) ensayos publicados en revistas de la especialidad, indicados en el programa de la asignatura como lecturas previas a la instancia presencial;

b) Actividad 2: A partir de la actividad anterior, se pusieron en relación las características del ensayo con una propuesta de acciones estratégicas para su escritura, de acuerdo con el modelo de producción de discurso académico (Tabla 1) y con bibliografía especializada en el género “ensayo" (CASTRO; HERNÁNDEZ; SÁNCHEZ, 2010; LARROSA, 2003), tal como se presenta en la Tabla 2: 
TABLA 2 - Modelización del ensayo académico

\begin{tabular}{|c|c|c|}
\hline $\begin{array}{c}\text { MODELO/ } \\
\text { REPRESENTACIÓN } \\
\text { MENTAL }\end{array}$ & & ACCIONES ESTRATÉGICAS \\
\hline $\begin{array}{l}\text { Situación comunicativa } \\
\text { (fundamentalmente } \\
\text { centrado en la función o } \\
\text { el propósito comunicativo } \\
\text { del ensayo y en la relación } \\
\text { autor/lector) }\end{array}$ & $\begin{array}{l}\text { Presentación de } \\
\text { a la revisión crít } \\
\text { Socialización y } \\
\text { Reflexión, análi } \\
\text { "El ensayista es } \\
\text { "La escritura de } \\
\text { (CASTRO; HE } \\
\text { [El ensayo] es v } \\
\text { propuesta intel }\end{array}$ & $\begin{array}{l}\text { un estado de conocimiento construido o reconstruido gracias } \\
\text { ca de planteamientos, ideas, teorías, opiniones, etc. } \\
\text { iscusión temática } \\
\text { is, crítica y opinión } \\
\text { an lector que escribe y un escritor que lee" (LARROSA, 2003) } \\
\text { ensayos se convierte en la escritura de varias lecturas" } \\
\text { (NÁNDEZ; SÁNCHEZ, 2010) } \\
\text { lorado como espacio discursivo de búsqueda, reflexión y } \\
\text { tuales (CASTRO; HERNÁNDEZ; SÁNCHEZ, 2010) }\end{array}$ \\
\hline $\begin{array}{l}\text { Evento de investigación } \\
\text { (fundamentalmente } \\
\text { centrado en el tratamiento } \\
\text { temático) }\end{array}$ & $\begin{array}{l}\text { Conocimiento } \\
\text { Comparación/ } \\
\text { Identificación d } \\
\text { Síntesis y evalu }\end{array}$ & $\begin{array}{l}\text { internalización de un sistema de ideas } \\
\text { ntraste entre conceptos } \\
\text { posturas, puntos de vista } \\
\text { ión crítica de la información }\end{array}$ \\
\hline \multirow{4}{*}{$\begin{array}{l}\text { Texto } \\
\text { (fundamentalmente } \\
\text { centrado en aspectos } \\
\text { estructurales- } \\
\text { organizacionales y de } \\
\text { citación y referenciación } \\
\text { bibliográficas) }\end{array}$} & Introducción & $\begin{array}{l}\text { Presentación de tema general, tema particular y estado de la } \\
\text { cuestión } \\
\text { Resumen de ideas principales } \\
\text { Exposición de un problema y de una solución/conclusión } \\
\text { anticipada } \\
\text { Planteo de interrogantes }\end{array}$ \\
\hline & Núcleo textual & $\begin{array}{l}\text { Construcción del aparato crítico: cita, exposición y/o } \\
\text { comentario de uno o más autores/fuentes } \\
\text { Construcción del aparato explicativo: explicación de } \\
\text { propuestas del aparato crítico } \\
\text { Construcción del aparato valorativo: análisis y comentario de } \\
\text { propuestas del aparato crítico }\end{array}$ \\
\hline & Conclusión & $\begin{array}{l}\text { Exposición de la idea principal del trabajo, juicios y opiniones } \\
\text { Resumen del trabajo } \\
\text { Evaluación de las ideas principales } \\
\text { Replanteo de interrogantes }\end{array}$ \\
\hline & Bibliografía & $\begin{array}{l}\text { Presentación de los datos bibliográficos completos de las } \\
\text { obras citadas, de acuerdo con el uso sistemático de un estilo } \\
\text { de referenciación }\end{array}$ \\
\hline $\begin{array}{l}\text { Corrección normativa } \\
\text { (fundamentalmente } \\
\text { centrado en ortografía y } \\
\text { sintaxis) }\end{array}$ & \multicolumn{2}{|c|}{$\begin{array}{l}\text { Reconocimiento de la interfaz sintaxis-semántica } \\
\text { Reconocimiento de estructuras argumentales } \\
\text { Relación entre sintaxis-puntuación } \\
\text { Uso de mayúsculas }\end{array}$} \\
\hline
\end{tabular}

Fuente: Elaboración propia 
c) Actividad 3: A partir de la actividad anterior, se realizó el análisis modélico de un ensayo publicado en una revista de la especialidad ${ }^{4}$, con la consigna de identificar estas características, y posteriormente se comentaron y se discutieron los resultados del análisis.

\subsubsection{Primera entrega y evaluación colaborativa de ensayos (setiembre):}

La Tabla 4 representa la grilla de evaluación, que fue diseñada de acuerdo con la modelización del ensayo realizada en el taller presencial de comprensión. Se acordó que en la grilla, los ítems "Función del ensayo" (correspondiente al modelo de situación comunicativa), "Relevancia de la temática tratada" y "Macroestructura/Coherencia informativa entre categorías genéricas" (correspondientes al modelo de evento) fueran evaluados y completados por las docentes arquitectas. Se trata de una grilla cualitativa, donde cada ítem se evalúa de acuerdo con la siguiente escala (Tabla 3):

TABLA 3 - Escala de calificación

\begin{tabular}{|l|l|}
\hline \multirow{2}{*}{ APROBADO } & MUY BUENO (MB) \\
\cline { 2 - 2 } & BUENO (B) \\
\hline \multirow{2}{*}{ DESAPROBADO } & REGULAR (R) \\
\cline { 2 - 2 } & INSUFICIENTE (I) \\
\hline
\end{tabular}

Fuente: Elaboración propia

${ }^{4}$ DIAZ, F. Miedo a la arquitectura. ARQ (Santiago), Santiago, n. 77, p. 13-14, abr. 2011. Disponible en: <http://bit.ly/2N4LcNE>. Acceso en: 22 dic. 2016. 
TABLA 4 - Grilla de evaluación

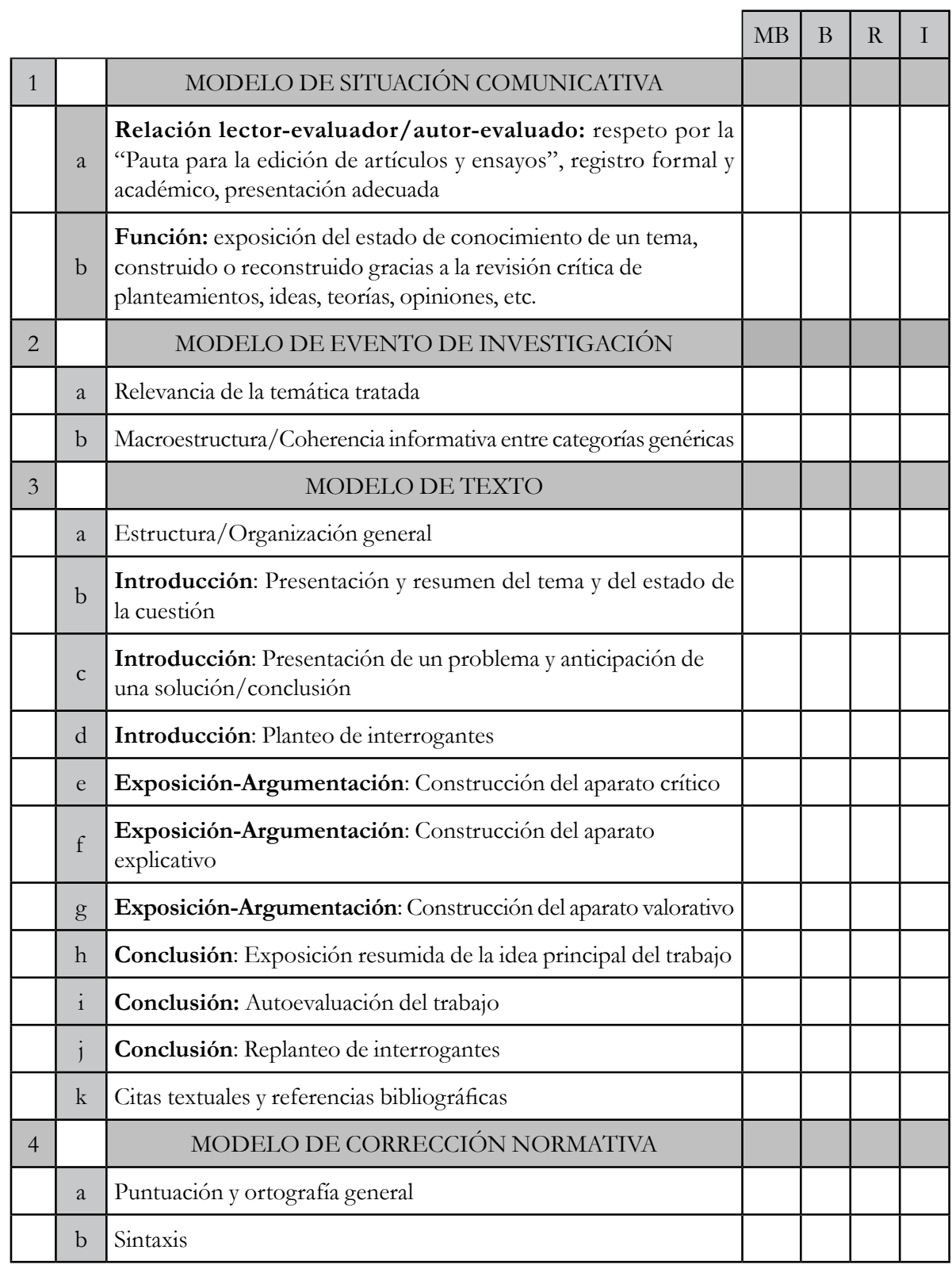

Fuente: Elaboración propia 
En la instancia de reunión presencial del tribunal, se discutió el trabajo de cada estudiante en particular, con las correspondientes tres grillas completadas con antelación y de manera individual por cada una de las docentes. Posteriormente, se consensuó el completamiento de una grilla analítica única con una evaluación holística anexa como "Comentarios, observaciones, recomendaciones" para ser entregada a cada uno de los doctorandos.

Sobre un total de trece doctorandos, diez presentaron ensayos para su evaluación en la primera instancia y las calificaciones obtenidas fueron las siguientes (Gráfico 1):

a) MUY BUENO: $1 / 10$

b) BUENO: 2/10

c) REGULAR: $3 / 10$

d) INSUFICIENTE: 4/10

GRÁFICO 1 - Calificaciones obtenidas en la primera entrega y evaluación

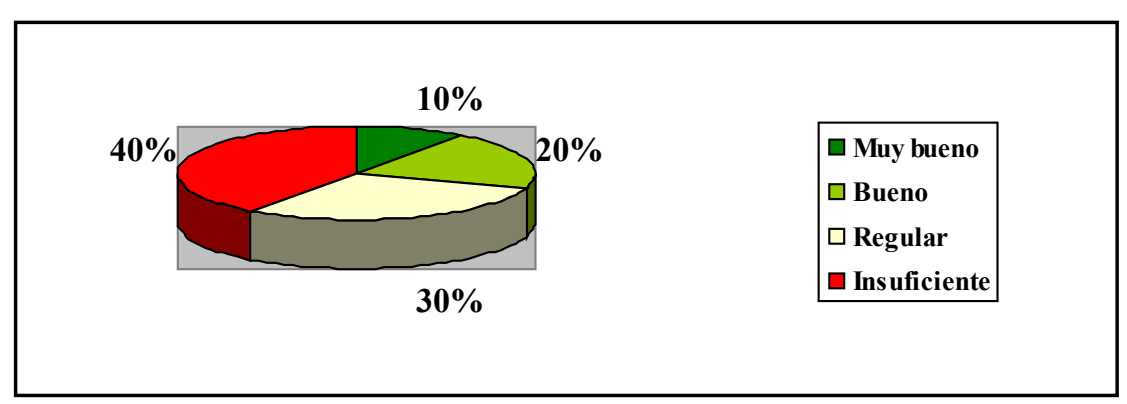

Fuente: Elaboración propia

A continuación, en la Tabla 5 se presentan las dificultades de los doctorandos en la escritura del ensayo en la primera instancia de entrega. Se agrupan los doctorandos de acuerdo con el resultado de la evaluación y las dificultades de acuerdo con los modelos o representaciones mentales correspondientes: 
TABLA 5 - Dificultades de los doctorandos y resultados de la evaluación en la primera instancia de escritura del ensayo

\begin{tabular}{|c|c|c|c|c|}
\hline & $\begin{array}{c}\text { MUY BUENO } \\
(10 \%)\end{array}$ & $\begin{array}{c}\text { BUENO } \\
(20 \%)\end{array}$ & $\begin{array}{c}\text { REGULAR } \\
(30 \%)\end{array}$ & $\begin{array}{c}\text { INSUFICIENTE } \\
(40 \%)\end{array}$ \\
\hline $\begin{array}{l}\text { Situación } \\
\text { comunicativa }\end{array}$ & & Función del ensayo & $\begin{array}{l}\text { Función del ensayo } \\
\text { Relación lector- } \\
\text { evaluador/autor- } \\
\text { evaluado (extensión del } \\
\text { ensayo, según la "Pauta } \\
\text { para la edición de } \\
\text { artículos y ensayos") }\end{array}$ & $\begin{array}{l}\text { Función del ensayo } \\
\text { (modalizaciones } \\
\text { deónticas, } \\
\text { afirmaciones } \\
\text { estadísticas, } \\
\text { porcentuales, etc. } \\
\text { sin fuente citada) } \\
\text { Relación lector- } \\
\text { evaluador/autor- } \\
\text { evaluado (extensión } \\
\text { del ensayo, según } \\
\text { la "Pauta para la } \\
\text { edición de artículos } \\
\text { y ensayos") }\end{array}$ \\
\hline $\begin{array}{l}\text { Evento de } \\
\text { investigación }\end{array}$ & & $\begin{array}{l}\text { Macroestructura/ } \\
\text { coherencia global }\end{array}$ & $\begin{array}{l}\text { Coherencia informativa } \\
\text { entre categorías } \\
\text { genéricas }\end{array}$ & $\begin{array}{l}\text { Coherencia } \\
\text { informativa entre } \\
\text { categorías genéricas } \\
\text { Relevancia temática } \\
\text { y disciplinar }\end{array}$ \\
\hline Texto & $\begin{array}{l}\text { Citas textuales } \\
\text { (citas de títulos } \\
\text { sin más datos, } \\
\text { citas largas a } \\
\text { doble espacio, } \\
\text { citas introducidas } \\
\text { por el verbo } \\
\text { "decir") }\end{array}$ & $\begin{array}{l}\text { Citas textuales } \\
\text { y referencias } \\
\text { bibliográficas (uso } \\
\text { asistemático de } \\
\text { estilos de citación y } \\
\text { referencia) } \\
\text { Estructura/ } \\
\text { organización (planteo } \\
\text { de interrogantes, } \\
\text { construcción del } \\
\text { aparato crítico, } \\
\text { construcción del } \\
\text { aparato valorativo, } \\
\text { títulos y subtítulos de } \\
\text { apartados sin marcas } \\
\text { de jerarquización, falta } \\
\text { de anclaje entre texto e } \\
\text { imágenes) }\end{array}$ & $\begin{array}{l}\text { Citas textuales } \\
\text { y referencias } \\
\text { bibliográficas (solo } \\
\text { se nombra el autor o } \\
\text { solo la cita sin el autor, } \\
\text { referencias de páginas } \\
\text { web solo con URL) } \\
\text { Estructura/ } \\
\text { organización } \\
\text { (presentación de un } \\
\text { problema y anticipación } \\
\text { de una solución, planteo } \\
\text { de interrogantes, } \\
\text { construcción del } \\
\text { aparato crítico, } \\
\text { construcción del } \\
\text { aparato valorativo, } \\
\text { exposición resumida } \\
\text { de la idea principal del } \\
\text { trabajo, autoevaluación } \\
\text { del trabajo, replanteo de } \\
\text { interrogantes) }\end{array}$ & $\begin{array}{l}\text { Citas textuales } \\
\text { y referencias } \\
\text { bibliográficas en } \\
\text { general } \\
\text { Estructura/ } \\
\text { Organización } \\
\text { general }\end{array}$ \\
\hline
\end{tabular}




\begin{tabular}{|c|c|c|c|c|}
\hline $\begin{array}{l}\text { Corrección } \\
\text { normativa }\end{array}$ & $\begin{array}{l}\text { Ortografía } \\
\text { (uso abusivo de } \\
\text { coma, palabras } \\
\text { compuestas } \\
\text { univerbales y } \\
\text { sintagmáticas, } \\
\text { mayúsculas) } \\
\text { Sintaxis } \\
\text { (concordancia } \\
\text { de número } \\
\text { en periodos } \\
\text { oracionales } \\
\text { largos, gerundio, } \\
\text { concordancia } \\
\text { entre antecedente } \\
\text { y pronombre } \\
\text { relativo, uso } \\
\text { excesivo de } \\
\text { “el cual”, su } \\
\text { femenino y } \\
\text { plurales) }\end{array}$ & $\begin{array}{l}\text { Ortografía (uso } \\
\text { abusivo de coma, coma } \\
\text { entre sujeto y verbo, } \\
\text { punto al finalizar } \\
\text { títulos o subtítulos) } \\
\text { Sintaxis (concordancia } \\
\text { de número en periodos } \\
\text { oracionales largos, } \\
\text { oraciones nominales } \\
\text { con múltiples } \\
\text { subordinadas sin } \\
\text { cierre, ambigüedad } \\
\text { de relativos con } \\
\text { múltiples antecedentes, } \\
\text { oraciones con } \\
\text { estructura argumental } \\
\text { incompleta) }\end{array}$ & $\begin{array}{l}\text { Ortografía (puntuación } \\
\text { general, apertura de } \\
\text { signos de interrogación, } \\
\text { palabras compuestas } \\
\text { univerbales y } \\
\text { sintagmáticas) } \\
\text { Sintaxis (concordancia } \\
\text { de género y número, } \\
\text { gerundio, locuciones } \\
\text { preposicionales) }\end{array}$ & $\begin{array}{l}\text { Ortografía (uso } \\
\text { abusivo de coma } \\
\text { para yuxtaponer } \\
\text { ideas sin conexión, } \\
\text { coma entre sujeto } \\
\text { y verbo, uso } \\
\text { alternante de signos } \\
\text { delimitadores } \\
\text { (guiones, rayas y } \\
\text { paréntesis), palabras } \\
\text { compuestas } \\
\text { univerbales y } \\
\text { sintagmáticas, } \\
\text { mayúsculas, } \\
\text { acentuación) } \\
\text { Sintaxis } \\
\text { (concordancia en } \\
\text { oraciones-párrafo, } \\
\text { gerundio, "donde” } \\
\text { como relativo no } \\
\text { locativo, locuciones } \\
\text { preposicionales, } \\
\text { verbos con } \\
\text { estructura } \\
\text { argumental } \\
\text { incompleta) }\end{array}$ \\
\hline
\end{tabular}

Fuente: Elaboración propia

\subsubsection{Ensayo académico II (marzo): Taller de escritura}

Se dedicó una jornada presencial para la revisión, consulta y reescritura de los doctorandos con las tres docentes evaluadoras. Se organizó una lista con turnos para que se hicieran las rotaciones necesarias, de manera que todos los doctorandos pudieran consultar todos los aspectos con cada docente $y$, una vez realizadas las consultas, abocarse a la tarea de reescritura.

\subsubsection{Segunda entrega y evaluación colaborativa de ensayos (mayo)}

Sobre un total de trece doctorandos, doce presentaron ensayos para su evaluación en la segunda instancia. De acuerdo con el detalle del apartado anterior, en esta segunda fecha de entrega, de los doce ensayos presentados, nueve corresponden a una segunda versión respecto de la primera fecha y tres corresponden a una primera entrega. De los nueve ensayos entregados como segunda versión, seis resultan aprobados y tres desaprobados, con lo 
cual se marca una diferencia significativa en calidad respecto de la primera entrega. De los tres ensayos entregados por primera vez, dos resultan aprobados y uno desaprobado. Las calificaciones obtenidas en esta instancia fueron las siguientes (Gráfico 2):
a) MUY BUENO: 5/12
b) BUENO: $3 / 12$
c) REGULAR: $3 / 12$
d) INSUFICIENTE: $1 / 12$

GRÁFICO 2 - Calificaciones obtenidas en la segunda entrega y evaluación

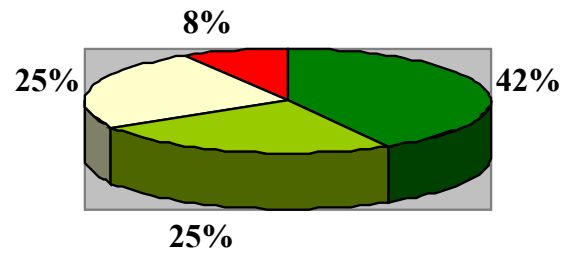

\begin{tabular}{|l|}
\hline$\square$ Muy bueno \\
$\square$ Bueno \\
$\square$ Regular \\
$\square$ Insuficiente
\end{tabular}

Fuente: Elaboración propia

A continuación, en la Tabla 6 se presentan las dificultades de los doctorandos en la escritura del ensayo en la segunda fecha de entrega. Se agrupan los doctorandos de acuerdo con el resultado de la evaluación y las dificultades de acuerdo con los modelos o representaciones mentales correspondientes: 
TABLA 6 - Dificultades de los doctorandos y resultados de la evaluación en la segunda instancia de escritura del ensayo

\begin{tabular}{|c|c|c|c|c|}
\hline & $\begin{array}{c}\text { MUY BUENO } \\
(42 \%)\end{array}$ & $\begin{array}{c}\text { BUENO } \\
(25 \%)\end{array}$ & $\begin{array}{l}\text { REGULAR } \\
(25 \%)\end{array}$ & $\begin{array}{c}\text { INSUFICIENTE } \\
(\mathbf{8 \% )}\end{array}$ \\
\hline $\begin{array}{l}\text { Situación } \\
\text { comunicativa }\end{array}$ & $\begin{array}{l}\text { Relación lector- } \\
\text { evaluador/ } \\
\text { autor-evaluado } \\
\text { (extensión del } \\
\text { ensayo, según } \\
\text { la "Pauta para } \\
\text { la edición de } \\
\text { artículos y } \\
\text { ensayos") }\end{array}$ & & \begin{tabular}{|l|} 
Función del ensayo \\
(modalizaciones \\
deónticas, afirmaciones \\
estadísticas, \\
porcentuales, etc. sin \\
fuente citada) \\
Relación lector- \\
evaluador/autor- \\
evaluado (extensión, \\
según la "Pauta para \\
la edición de artículos \\
y ensayos"; falta \\
de corrección de \\
dificultades señaladas \\
en la primera versión
\end{tabular} & $\begin{array}{l}\text { Relación lector-evaluador/ } \\
\text { autor-evaluado (falta de } \\
\text { corrección de dificultades } \\
\text { señaladas en la primera } \\
\text { versión) }\end{array}$ \\
\hline $\begin{array}{l}\text { Evento de } \\
\text { investigación }\end{array}$ & & $\begin{array}{l}\text { Coherencia } \\
\text { informativa } \\
\text { entre categorías } \\
\text { genéricas }\end{array}$ & $\begin{array}{l}\text { Coherencia informativa } \\
\text { entre categorías } \\
\text { genéricas }\end{array}$ & $\begin{array}{l}\text { Coherencia informativa } \\
\text { entre categorías genéricas } \\
\text { Relevancia temática y } \\
\text { disciplinar }\end{array}$ \\
\hline Texto & \begin{tabular}{l}
\multicolumn{1}{c}{ Citas textuales } \\
y referencias \\
bibliográficas \\
(citas de títulos o \\
autores sin más \\
datos, confusión \\
entre bibliografía \\
y referencias) \\
Estructura/ \\
organización \\
(exposición \\
resumida de la \\
idea principal \\
del trabajo, \\
autoevaluación \\
del trabajo, \\
replanteo de \\
interrogantes)
\end{tabular} & \begin{tabular}{l}
\multicolumn{1}{c}{ Citas textuales } \\
y referencias \\
bibliográficas \\
(citas de títulos \\
o autores sin \\
más datos, uso \\
asistemático de \\
estilos de citación \\
y referencia) \\
Estructura/ \\
organización \\
(presentación \\
de un problema \\
y anticipación \\
de una solución, \\
planteo de \\
interrogantes)
\end{tabular} & \begin{tabular}{l}
\multicolumn{1}{|c}{ Citas textuales } \\
y referencias \\
bibliográficas (solo \\
se nombra el autor o \\
solo la cita sin el autor, \\
paréntesis, citas literales \\
sin vinculación explícita \\
con el texto) \\
Estructura/ \\
organización \\
(presentación de un \\
problema y anticipación \\
de una solución, planteo \\
de interrogantes, \\
construcción del \\
aparato crítico, \\
construcción del \\
aparato valorativo, \\
exposición resumida \\
de la idea principal del \\
trabajo, autoevaluación \\
del trabajo, replanteo de \\
interrogantes)
\end{tabular} & $\begin{array}{l}\text { Citas textuales y } \\
\text { referencias bibliográficas } \\
\text { (uso asistemático de estilos } \\
\text { de citación y referencia, } \\
\text { referencias bibliográficas } \\
\text { inexistentes) } \\
\text { Estructura/Organización } \\
\text { general }\end{array}$ \\
\hline
\end{tabular}




\begin{tabular}{|c|c|c|c|c|}
\hline $\begin{array}{l}\text { Corrección } \\
\text { normativa }\end{array}$ & $\begin{array}{l}\text { Ortografía } \\
\text { (punto al } \\
\text { finalizar títulos o } \\
\text { subtítulos) } \\
\text { Sintaxis } \\
\text { (gerundio) }\end{array}$ & $\begin{array}{l}\text { Ortografía (uso } \\
\text { abusivo de coma, } \\
\text { acentuación) } \\
\text { Sintaxis } \\
\text { (oraciones- } \\
\text { párrafo, gerundio) }\end{array}$ & $\begin{array}{l}\text { Ortografía (uso } \\
\text { abusivo de coma para } \\
\text { yuxtaponer ideas sin } \\
\text { conexión, coma entre } \\
\text { sujeto y verbo, punto } \\
\text { al finalizar títulos o } \\
\text { subtítulos) } \\
\text { Sintaxis (concordancia } \\
\text { de género en } \\
\text { pronombres relativos y } \\
\text { de número, oraciones } \\
\text { nominales con } \\
\text { múltiples subordinadas } \\
\text { sin cierre, gerundio, } \\
\text { verbos con estructura } \\
\text { argumental incompleta) }\end{array}$ & $\begin{array}{l}\text { Ortografía (uso abusivo } \\
\text { de coma para yuxtaponer } \\
\text { ideas sin conexión, coma } \\
\text { entre sujeto y verbo, } \\
\text { mayúsculas) } \\
\text { Sintaxis (oraciones-párrafo, } \\
\text { gerundio, locuciones } \\
\text { preposicionales, verbos } \\
\text { con estructura argumental } \\
\text { incompleta) }\end{array}$ \\
\hline
\end{tabular}

Fuente: Elaboración propia

\subsubsection{Tercera entrega (definitiva) y evaluación colaborativa de ensayos (setiembre)}

De los cuatro doctorandos que resultaron no aprobados en la segunda instancia, solo una presentó una tercera versión del ensayo y mantuvo la calidad de su escrito.

Con esta tercera instancia de presentación y evaluación se cerró la fase interactiva del proceso de intervención.

\subsection{Fase post-activa o de evaluación de la intervención}

Las calificaciones obtenidas por los doctorandos en el transcurso del proceso constituyen indicadores de la calidad de sus producciones escritas.

Considerando comparativamente esta variable, los datos obtenidos en la fase interactiva nos muestran que, sobre un total de nueve casos de doctorandos que sometieron a evaluación por segunda vez su ensayo, se registró:

a) Aumento de la calidad del escrito. En esta categoría, no solo es importante el registro de casos de aumento de la calidad, sino principalmente destacar el salto altamente significativo en la escala de calificación: 
- De Regular a Muy Bueno: 3

- De Insuficiente a Bueno: 1

- De Insuficiente a Regular: 1

b) Mantenimiento de la calidad del escrito. En general, en estos casos los doctorandos no tuvieron en cuenta la mayoría de las indicaciones señaladas o bien en los comentarios realizados en la corrección de la primera versión, o bien en la instancia presencial del taller de escritura:

- Bueno: 1

- Muy bueno: 1

- Insuficiente: 1

c) Disminución de la calidad del escrito. En esta categoría se dio un único caso. La doctoranda no tuvo en cuenta la mayoría de los señalamientos realizados, tanto en la corrección de la primera versión, como en la instancia del taller de escritura. En la primera instancia se la había calificado con "Bueno", dándole expresamente un "voto de confianza" para que reescribiera una segunda versión, con el objetivo de que aumentara la calidad de un escrito con muchas deficiencias en distintos niveles. Uno de los señalamientos importantes había sido la escasa discusión teórica de la temática, lo que llevó a la doctoranda a incorporar gran cantidad de citas en la mayoría de los casos de manera arbitraria y con deficiencias formales, inclusive citas de segunda mano con referencias bibliográficas inexistentes. Esto impactó sensiblemente de manera negativa en otros criterios de evaluación, fundamentalmente en la construcción del aparato crítico, la construcción del aparato valorativo y la exposición resumida de la idea principal del trabajo.

En el Gráfico 3 se registran los datos correspondientes a la medición de la variación de la calidad de los escritos durante el proceso de intervención, en relación con las calificaciones obtenidas: 
GRÁFICO 3 - Medición de la variación de la calidad de los ensayos

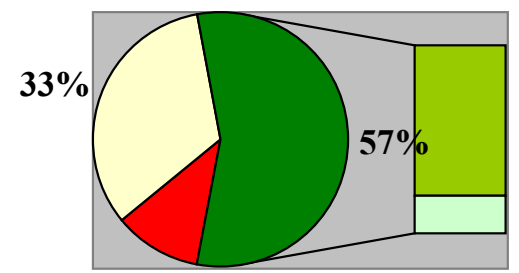

$11 \%$
$45 \%$

$11 \%$

\begin{tabular}{|l|}
\hline Disminución \\
$\square$ Mantenimiento \\
$\square$ Aumento de 2 niveles \\
$\square$ Aumento de 1 nivel \\
\hline
\end{tabular}

Fuente: Elaboración propia

\section{Conclusiones}

Retomando las preguntas preliminares y los propósitos planteados al inicio, me gustaría cerrar este trabajo con algunas conclusiones respecto de las dificultades de los doctorandos en la tarea de escritura por un lado, y por otro, respecto de la evolución del proceso de intervención en relación con la calidad de los ensayos.

Si consideramos los criterios de evaluación como criterios de descripción y comparación para identificar y, de alguna manera, medir las dificultades de los doctorandos en la escritura de ensayos, los resultados sugieren que los criterios más interactivos, es decir, aquellos configurados a partir del modelo de situación comunicativa, solo se manifestaron recurrentemente como dificultades en los niveles de menor rendimiento de la escala de calificación. A su vez, los criterios más organizacionales, relacionados con los distintos movimientos del género "ensayo académico", como la introducción, la construcción del dispositivo expositivoargumentativo y las conclusiones, si bien se advirtieron más recurrentemente como ámbitos de dificultades en los niveles de menor rendimiento, también se presentaron en algunos casos del grupo evaluado con "Bueno". Este mismo comportamiento pudo percibirse en lo que respecta a criterios más semánticos, como los relacionados con la temática, su relevancia y desarrollo coherente. En cuanto a los criterios más formales, relacionados con sistemas fuertemente estructurados, como las citas textuales, las referencias bibliográficas y los aspectos normativos, es notorio el hecho 
de que se evidenciaron como dificultades en los cuatro grupos de la escala de evaluación. Particularmente en este último dominio considero que es importante detenernos, porque no es frecuente encontrarlo desarrollado de manera analítica o sistemática en publicaciones sobre producción académica escrita. Ciertamente mi objetivo no es propiciar la incorporación de gramática y ortografía como contenidos "per se" a las clases de escritura en el posgrado. Pero sí propongo que a partir de estos datos consideremos la posibilidad de una apertura hacia una normativa situada, relevante y contextualizada en la tarea de la escritura académica desde una mirada sociocognitiva, incorporándola como un tipo más de representación mental a ser trabajada colaborativamente en los talleres de producción académica escrita. Sin ánimo de caer en generalizaciones, parecería que, ante la tarea de la escritura académica en el posgrado, los profesionales tienden a minimizar el peso del aspecto normativo en relación con el del temáticoconceptual y, en consecuencia, emprenden la tarea de la escritura a partir de la elaboración de un "modelo" de sistema de la lengua encapsulado, una representación mental estratégica de una normativa inocua, desvinculada de la comunicación del evento de investigación, sobre la cual no ejercería impacto alguno. El desarrollo del proceso de intervención objeto de este estudio nos muestra que el docente de un taller de escritura en el posgrado puede, efectivamente, identificar y sistematizar dificultades recurrentes en la apropiación de la gramática y la ortografía, socializarlas y trabajarlas como tales. Se trata, en definitiva, de "desestigmatizar" la normativa, promoviendo la concientización de la escritura académica como un tipo especial de escritura, que por esa misma especialidad selecciona recursos específicos del sistema de la lengua, sobre los que es necesario reflexionar para poder utilizarlos de manera redituable en una situación de interacción muy particular, como es la que se da entre un lector-evaluador y un autor-evaluado. No me gustaría dejar de mencionar que entre las últimas investigaciones en literacidad, un ejemplo de preocupación por el estudio de las dificultades de los estudiantes con las particularidades normativas de la redacción académica es el proyecto "Estilector" (RENAU, 2015). En este proyecto se ha desarrollado una interfaz de acceso libre para asistir la redacción de textos académicos en la detección de problemas ortográficos, gramaticales y algunos aspectos puntuales de vocabulario, como riqueza léxica y combinatoria; además, el programa entrega explicaciones, apoyo bibliográfico y recursos en línea a los usuarios (RENAU, 2016). 
Para pasar ahora a las consideraciones acerca de la evolución del proceso de intervención en relación con la calidad de los ensayos, recordemos los datos que discutimos anteriormente: en la primera instancia, un 30\% resultó aprobado (uno con "Muy bueno" y dos con "Bueno") y un $70 \%$ resultó desaprobado (tres con "Regular" y cuatro con "Insuficiente"); mientras que en la segunda instancia, hubo un $67 \%$ de aprobados (cuatro con "Muy bueno" y dos con "Bueno") y un 33\% desaprobados (dos con "Regular" y uno con "Insuficiente"). Estos datos muestran que prácticamente se invirtió satisfactoriamente la relación aprobadosdesaprobados entre una instancia de intervención y la siguiente. Además, cinco ensayos aumentaron significativamente en calidad, tres la mantuvieron y solo uno disminuyó en calidad, con lo cual es importante destacar que, a partir del proceso de intervención, no solo aumentó la cantidad de ensayos aprobados, sino que aumentó también la cantidad de ensayos evaluados con máxima calificación.

Finalmente, no resulta ocioso recordar una vez más que se ha llevado adelante un estudio de caso con resultados que no aspiran a ser generalizables; teniendo en cuenta, fundamentalmente, que en los cursos de posgrado trabajamos con grupos reducidos de estudiantes y que, en consecuencia, una generalización de resultados violentaría el principio de significación estadística. Pero al concebirlo metodológicamente como un estudio de caso instrumental, los resultados obtenidos sí nos permiten abrir una puerta para repensar el abordaje de la enseñanza, el aprendizaje y la evaluación de la escritura académica en el posgrado, un problema suficientemente identificado como tal en la bibliografía especializada, según ya hemos visto. Entonces, sin ánimo de generalizar, pero sí con el de aportar datos empíricos a la discusión teórica y conceptual sobre alfabetización académica en el nivel superior, podemos interpretar los resultados aquí expuestos como fuertes indicadores de que el proceso de escritura en el posgrado es, efectivamente, demandante y complejo, y de que podemos, también, contribuir a mejorar la calidad de los escritos llevando a cabo un entrenamiento estratégico sistemático, sostenido al menos en tres conjuntos de acciones. En primer lugar, una modelización explícita del proceso de producción. Aquí se ha propuesto un modelo sociocognitivo que iterrelaciona la comprensión y la producción de discurso académicocientífico, basado en representaciones mentales de la situación comunicativa, el evento de investigación, el texto y la corrección normativa. Un segundo 
conjunto de acciones es el que se relaciona con una evaluación comprometida y consistente con la explicitación del proceso de producción. En este sentido, la propuesta contempla la constitución de un equipo interdisciplinario de seguimiento y evaluación, a cargo del diseño de una pauta de edición para el género trabajado y de grillas analíticas basadas en los criterios de la modelización. De esta manera, se pudo evaluar y dar a conocer el desempeño en cada dimensión, destacando las fortalezas y las debilidades puntuales de las producciones escritas. Por último, un tercer grupo de acciones es el que contempla las instancias de discusión, de reflexión y de reescritura, tanto en la forma presencial de taller de escritura como a distancia en el envío y el reenvío de las distintas versiones. Estas instancias se desarrollaron sobre la base de las devoluciones de las grillas de evaluación y de los comentarios escritos a las versiones presentadas, y permitieron orientar el proceso de escritura de los doctorandos hacia los estándares de calidad esperados.

\section{Referencias}

ALZATE PIEDRAHITA, M; ARBELAEZ GÓMEZ, M.; GÓMEZ MENDOZA, M.; ROMERO LOAIZA, F. Intervención, mediación pedagógica y los usos del texto escolar. Revista Iberoamericana de Educación, Madrid, v. 37, n. 3, p. 1-15, 2005. Disponible en: <https://goo.gl/1P8ZqB>. Acceso en: 2 jul. 2016.

BAZERMAN, C. Liberal education and communication against the disciplines: a view from the world of writing. Communication Education, Washington, v. 54, n. 1, p. 86-91, 2005. Doi: https://doi.org/10.1080/03634520500077099

BAZERMAN, C. Genre and cognitive development: beyond writing to learn. Pratiques, Metz, p. 127-138, 2009. Disponible en: <https://goo.gl/FjE2bC>. Acceso en: 20 dic. 2017.

BAZERMAN, C.; BONINI, A.; FIGUEIREDO, D. (Ed.). Genre in a changing world. Fort Collins: The WAC Clearinghouse, 2009.

BHATIA, V. Analysing genre: language use in professional settings. London: Longman, 1993.

BOSIO, I. (Dir.). Construcción de un Corpus de Discurso Académico escrito y oral de la UNCuyo con metodología de lingüistica de Corpus. Proyecciones hacia ámbitos cientificos y didáctico-pedagógicos. Proyecto SECTYP 06/G718, Mendoza: Universidad Nacional de Cuyo, 2016-2018. Disponible en: <http://bit.ly/2IONVrK>. Acceso en: 20 dic. 2017. 
CARLINO, P. Alfabetización académica: un cambio necesario, algunas alternativas posibles. Educere, Mérida, año 6, n. 20, p. 409-420, 2003. Disponible en: <https:// goo.gl/1RvqTJ>. Acceso en: 3 nov. 2017.

CARLINO, P. Alfabetización académica diez años después. Revista Mexicana de Investigación Educativa, Ciudad de México, v. 18, n. 57, p. 355-381, 2013. Disponible en: <https://goo.gl/f5dXDW>. Acceso en: 5 set. 2017.

CASTELLÓ, M. Los retos actuales de la alfabetización académica: estado de la cuestión y últimas investigaciones. Enunciación, Bogotá, v. 19, n. 2, p. 346-365, 2014. Disponível em: <https://goo.gl/mH4FZ2>. Acceso en: 20 nov. 2017.

CASTRO, M.; HERNÁNDEZ, L.; SÁNCHEZ, M. El ensayo como género académico: una aproximación a las prácticas de escritura en la universidad pública mexicana. En: PARODI, G. (Ed.). Alfabetización académica y profesional en el siglo XXI: leer y escribir desde las disciplinas. Santiago: Ariel, 2010. p. 49-70.

CUBO, L. (Ed.). Los textos de la Ciencia. Córdoba: Comunicarte, 2005.

CUBO, L.; BOSIO, I. La tesis como clase textual y su proceso de escritura. En: CUBO, L.; PUIATTI, H.; LACON, N. (Ed.). Escribir una tesis: manual de estrategias de producción. Córdoba: Comunicarte, 2012. p. 11-34.

CUBO, L.; CASTRO DE CASTILLO, E. Escribir en la Universidad, un nuevo desafío. En: CUBO DE SEVERINO, L. (Ed.). Los textos de la Ciencia. Córdoba: Comunicarte, 2005. p. 16-20.

CUBO, L.; PUIATTI, H.; LACON, N. (Ed.). Escribir una tesis: manual de estrategias de producción. Córdoba: Comunicarte, 2012.

ELLIOT, J. La investigación-acción en educación. 4. ed. Madrid: Ediciones Morata, 2000.

GRABE, W.; KAPLAN, R. Theory \& practice of writing: an applied linguistic perspective. Londres: Longman, 1996.

HALLIDAY, M. A. K.; MARTIN, J. R. Writing science: literacy and discursive power. Pittsburgh: University of Pittsburg Press, 1993.

HAYES, J. R. A new framework for understanding cognition and affect in writing. En: LEVY, C.; RANSDELL, S. (Ed.). The science of writing: theories, methods, individual differences, and applications. Hillsdale: Lawrence Erlbaum Associates, 1996. p. 1-27.

HYLAND, K. Disciplinary discourses: writer stance in research articles. En: CANDLIN, C.; HYLAND, K. (Ed.). Writing: texts, processes and practices. London: Longman, 1999. p. 99-121.

HYLAND, K. Genre-based pedagogies: a social response to process. Journal of Second Language Writing, Amsterdam, n. 12, p. 17-29, 2003. 
IBÁÑEZ, R.; GONZÁLEZ, C. Alfabetización disciplinar en la formación inicial docente: leer y escribir para aprender. Valparaíso: Ediciones Universitarias de Valparaíso, 2017.

LARROSA, J. El ensayo y la escritura académica. Revista Propuesta Educativa, Buenos Aires, año 12, n. 26, p. 20-34, 2003.

LATORRE, G.; ALU, M. Entrevista al doctor en Lingüística Federico Navarro: la formación en la lectura y escritura académica. Fundación Lúminis, Buenos Aires, 2015. Disponible en: <https://goo.gl/A82cW9>. Acceso en: 3 oct. 2016.

MANGHI, D. Géneros en la enseñanza escolar: configuración de significados en clases de historia y biología desde una perspectiva multimodal. Revista Signos, Valparaíso, v. 6, n. 42, p. 236-247, 2013. Disponible en: <https://goo.gl/ aKKUCW>. Acceso en: 8 dic. 2017.

MARTIN, J. R.; ROSE, D. Working with discourse: meaning beyond the clause. London: Continuum, 2003.

MILIAM, M.; CAMPS, A. (Ed.). Elpapel de la actividad metalingüistica en el aprendizaje de la escritura. Rosario: Homo Sapiens, 2000.

NAVARRO, F. (Ed.). Manual de escritura para carreras de humanidades. Buenos Aires: Editorial de la Facultad de Filosofía y Letras, Universidad de Buenos Aires, 2014.

NEIMAN, G.; QUARANTA, G. Los estudios de caso en la investigación sociológica. En: VASILACHIS DE GIALDINO, I. (Coord.). Estrategias de investigación cualitativa. Buenos Aires: Gedisa, 2007. p. 213-238.

NOTHSTEIN, S.; VALENTE, E. La producción de escritos en postgrados internacionales: la incidencia de las tradiciones académicas en la apropiación y producción de saberes. Revista Signos, Valparaíso, v. 49, supl. 1, p. 127-148, 2016. Disponible en: < https://goo.gl/5o5GtK>. Acceso en: 5 ago. 2017.

OLAIZOLA, A. Alfabetización académica en entornos digitales. Buenos Aires: Universidad de Palermo, 2011. Disponible en: < https://goo.gl/8RbVAd>. Acceso en: 7 dic. 2017.

PADILLA, C.; DOUGLAS, S.; LÓPEZ, E. Elaborar ponencias en la clase universitaria: la mirada de docentes y estudiantes en una experiencia de investigaciónacción. Lecturay Vida, La Plata, v. 31, n. 2, p. 6-17, 2010. Disponible en: < https:// goo.gl/fwUpeY>. Acceso en: 2 set. 2016.

PALTRIDGE, B. Genre, frames and writing in research settings. Amsterdam: John Benjamins, 1997. Doi: https://doi.org/10.1075/pbns.45 
PALTRIDGE, B. Genre and the language learning classroom. Ann Arbor: University of Michigan Press, 2001. Doi: https://doi.org/10.3998/mpub.23749

PARODI, G. (Ed.). Géneros académicos y géneros profesionales: accesos discursivos para saber y hacer. Valparaíso: Ediciones Universitarias de Valparaíso, 2008.

PARODI, G. (Ed.). Alfabetización académica y profesional en el siglo XXI: leer y escribir desde las disciplinas. Santiago: Academia Chilena de la Lengua, 2010.

PARODI, G. (Dir.) Creación de una base de datos de "corpus de aprendientes en web" para el desarrollo de estrategias de comprensión y producción de textos orales y escritos. Proyecto de Investigación en Docencia, Valparaíso: Pontificia Universidad Católica de Valparaíso, 2011. Disponible en: < https://goo.gl/mukJQC>. Acceso en: 20 dic. 2017

PÉREZ GAZTELU, E.; ZULAIKA IJURKO, E. De dónde partimos: las prácticas letradas académicas de los estudiantes de bachillerato. En: BALLANO, I.; MUÑOZ, I. (Ed.). Escribir en el contexto académico. Bilbao: Publicaciones de la Universidad de Deusto, 2014. p. 53-88.

RENAU, I. (Dir.) Estilector: una herramienta de aprendizaje para la redacción y traducción de textos destinada a estudiantes universitarios. Proyecto de Innovación en Docencia Universitaria, Valparaíso: Pontificia Universidad Católica de Valparaíso, 2015. Disponible en: < https://goo.gl/7sfVJe>. Acceso en: 3 dic. 2017.

RENAU, I. (Dir.). Estilector: programa de ayuda a la redacción de textos académicos. 2016. Disponible en <http://bit.ly/2MLud2q>. Acceso en: 3 dic. 2017.

SCHRÖDER, H. Linguistic and text-theorical research on languages for special purposes: a thematic and bibliographical guide. En: SCHRÖDER, H. (Ed.). Subject-oriented texts: languages for special purposes and text theory. Berlin: Walter de Gruyter, 1991. p. 1-48. Doi: https://doi.org/10.1515/9783110858747

SOSA, S.; MAZZUCHINO, M. Lectura y escritura en la Universidad: prácticas discursivas. Córdoba: Comunicarte, 2017.

SOTOMAYOR, C. et al. Evaluación analítica de la escritura de estudiantes de $4^{\circ}$ año básico en Chile. Onomázzein, Santiago, v. 34, p. 38-425, 2016. Disponible en: <https://goo.gl/B8Lakq>. Acceso en: 29 nov. 2017.

SWALES, J. Genre analysis: english in academic and research settings. Cambridge: Cambridge University Press, 1990.

SWALES, J. Research genres: explorations and applications. Cambridge: Cambridge University Press, 2004. Doi: https://doi.org/10.1017/CBO9781139524827 
TAPIA-LADINO, M. Los comentarios escritos: género orientado a la consecución de otro género en el proceso de la escritura académica. Onomázein, Santiago, v. 30, p. 254-268, 2014. Disponible en: <https://goo.gl/TJNHDQ>. Acceso en: 20 nov. 2017.

TAPIA-LADINO, M.; ARANCIBIA GUTIÉRREZ, B.; CORREA PÉREZ, R. Rol de los comentarios escritos en la construcción de la tesis desde la perspectiva de estudiantes tesistas y profesores guía. Universitas Psychologica, Bogotá, v. 15, n. 4, p. 1-13, 2016. Disponible en: <https://goo.gl/gL8qfi> . Acceso en: 20 nov. 2017.

TAPIA-LADINO, M. et al. Reacciones de los estudiantes a los comentarios escritos que proveen docentes de lenguaje en enseñanza secundaria chilena. Enunciación, Bogotá, v. 19, n. 1, p. 39-52, 2014. Disponible en: <https://goo.gl/ NiSUPp>. Acceso en: 20 nov. 2017.

VAN DIJK, T.; KINTSCH, W. Strategies of discourse comprehension. New York: Academic Press, 1983.

VENEGAS, R. (Dir.) Hacia un modelo de análisis semiantomatizado de la organización retórico-discursiva de los trabajos finales de grado de licenciatura en ciencias y bumanidades. Proyecto FONDECYT 1140967, Valparaíso: Pontificia Universidad Católica de Valparaíso, 2016. Disponible en: < https://goo.gl/EDyFLR>. Acceso en: 2 dic. 2017.

VENEGAS, R. et al. Escribir desde la Pedagogía del Género: guías para escribir el trabajo final de grado en licenciatura. Valparaíso: Ediciones Universitarias de Valparaíso, 2015.

Data de submissão: 25/12/2017. Data de aprovação: 03/05/2018. 


\section{ANEXO \\ Pautas para la edición de artículos y ensayos}

Los artículos y ensayos deben ajustarse a las siguientes normas de edición:

1. Los ensayos o artículos deberán tener una extensión entre 4.000 y 6.000 palabras.

2. El formato de página será el del procesador de texto por defecto (hojas A 4, 2,54 cm de margen, sin separación entre párrafos). La fuente a utilizar es Times New Roman 12, con interlineado 1,5.

3. El encabezado de cada trabajo, en interlineado sencillo y negrita, estará constituido por el título, nombre del autor y palabras clave (entre 3 y 5). Se recomienda elegir títulos y subtítulos sucintos y "transparentes" desde el punto de vista temático.

4. Luego del encabezado, se presentará el desarrollo estructurado en introducción, capítulos o secciones correspondientes, conclusiones y referencias bibliográficas.

5. Las citas se incluirán en el texto, de acuerdo con el siguiente formato: Apellido, año de edición, página citada (Ejemplo: Tapia 2011: 45). La referencia bibliográfica completa correspondiente a cada cita deberá incluirse en la sección final "Referencias bibliográficas".

6. Las referencias bibliográficas se realizarán de acuerdo con las normas APA, en letra Times New Roman 10, interlineado sencillo.

7. Se sugiere utilizar la menor cantidad posible de notas, que, en el caso de incluirse, deberán ir al pie del artículo o ensayo (no al final), en Times New Roman 10 y no podrán tener una extensión superior a 60 palabras por cada nota.

8. Los trabajos que contengan términos, siglas, valores, etc. deberán describir y/o explicar sus significados solo en el primer uso que se haga de los mismos, a fin de asegurar la total comprensión a los lectores del problema y origen del trabajo.

9. El contenido gráfico podrá estar compuesto por fotos, figuras (planos, bosquejos, dibujos, etc.), tablas y/o esquemas (o diagramas), que deberán ser perfectamente nítidos y formar parte del contenido del documento, evitando ilustraciones mudas ajenas a este y garantizando su vinculación 
con el texto. Los autores podrán incluir hasta un máximo de 6 elementos gráficos en total. Todo el material gráfico deberá ser insertado en el archivo de texto y deberá estar numerado consecutivamente según su tipo (Ejemplo: Cuadro 1, Cuadro 2, Tabla 1, Plano 1, Tabla 2, Mapa 1, Cuadro 3, Mapa 2, etc.), e identificado a través de una leyenda explicativa al pie de la imagen, que indique la fuente de origen en cada caso, en letra Times New Roman 9 negrita. Ejemplo:

\begin{tabular}{|c|c|c|c|}
\hline \multirow{3}{*}{ ARQUITECTURA } & \multirow[b]{2}{*}{ Existencia } & \multirow{2}{*}{$\begin{array}{l}\text { DISEÑO } \\
\text { CONSTRUCCION }\end{array}$} & \multirow{2}{*}{$\begin{array}{l}\text { El aspecto formal o la pura posibilidad de llegar } \\
\text { a ser Arquitectura, pero a la vez la única } \\
\text { posibilidad desde la cual puede ser 'dicha' la } \\
\text { arquitectonicidad. } \\
\text { El aspecto existencial o la manifestación } \\
\text { material de Arquitectura, un aspecto } \\
\text { logicamente posterior al Diseno pero visible en } \\
\text { la documentación de obra. }\end{array}$} \\
\hline & & & \\
\hline & Valor & HABITAR & $\begin{array}{l}\text { El aspecto del valor o la función en tanto } \\
\text { necesidad social que puede valorarse en una } \\
\text { instancia posterior a la construcción o 'entre } \\
\text { lineas'en la documentación de diseno. }\end{array}$ \\
\hline \multicolumn{4}{|c|}{ Cuadro 2} \\
\hline \multicolumn{4}{|c|}{$\begin{array}{l}\text { Una primera partición triádica del signo "Arquitectura" en sus tres aspectos o subsignos } \\
\text { (Guerri 2001:226) }\end{array}$} \\
\hline
\end{tabular}

